\title{
Relationship between Vitamin D Status and Blood Pressure, Age, Physical Activity, and Nutritional Status in Saudi Males and Females
}

\author{
Sahar Alsedairy ${ }^{1}$, Nawal Al Badr ${ }^{1}$, Zobida Bekhaeit ${ }^{2}$, Manal Binobead ${ }^{1}$, Hissah Aldubaykhi ${ }^{1}$ and Tahani Aljurbua ${ }^{1 *}$ \\ ${ }^{1}$ Department of Food Science and Human Nutrition, King Saud University, Saudi Arabia \\ ${ }^{2}$ National Centre of Food Research, Sudan \\ *Corresponding author: Tahani Aljurbua, Department of Food Science and Human Nutrition, King Saud University, Riyadh, Saudi Arabia
}

Submission: May 29, 2018; Published: July 18, 2018

\begin{abstract}
This work is an attempt to find correlations among vitamin D status (deficiency/insufficiency), body mass index, age, blood pressure, sex, and physical activities in the male and female Saudi population. A total of 55 adult patients aged 25-70 years (37 women and 18 men) were recruited from an outpatient clinic of King Khalid and King Abdul- Aziz Hospitals, Riyadh, Saudi Arabia. They were asked to answer a survey to indicate their exposure to sun, physical activities and nutritional status related to vitamin D. Their BMI and diastolic and systolic blood pressure were measured. They were divided into two age groups ( $<40$ years old and $>40$ years old). The obtained data demonstrate that while a non-significant correlation was observed between vitamin D deficiency and BMI in young participants, a significant correlation was recorded in the older group. Males deficient in vitamin D were more susceptible to having high blood pressure than females. A relationship between vitamin D status and physical activities in the two studied age groups was also observed. The inverse relationship between vitamin D levels and hypertension in older males can help to suggest supplementation with vitamin D and encouragement for participation in physical activities as a preventive strategy in the Saudi population with a common and repeatedly reported impaired vitamin D status(deficiency/insufficiency).
\end{abstract}

Keywords: Vitamin D; Blood pressure; Body mass index; Physical activities; Sex; Age

Abbreviations: WHO: World Health Organization; BMI: Body Mass Index

\section{Introduction}

Cardiovascular disease causes nearly 17 million deaths, almost one-third of all deaths worldwide [1]. Among these deaths, complications from high blood pressure account for 9.4 million deaths per year [2]. High blood pressure accounts for $45 \%$ of heart disease deaths and $51 \%$ of stroke deaths [1]. High blood pressure has also been associated with an increased risk of chronic kidney disease $[3,4]$

Hypertension is a global public health problem. Roughly one billion people worldwide are estimated to have clinically significant elevations in blood pressure, with approximately 50 million of them living in the United States [5]. In clinical trials, antihypertensive therapy can result in reductions in the incidence of stroke, myocardial infarction, and heart failure [6]. In a meta-analysis study, a $10 \mathrm{mmHg}$ reduction in systolic BP (SBP) reduced the risk of major cardiovascular disease by $20 \%$, coronary heart disease by $17 \%$, stroke by $27 \%$, and heart failure by $28 \%$, which led to a significant $13 \%$ reduction in all-cause mortality in the populations studied [7].
According to WHO records, the number of people with hypertension increased from 600 million in 1980 to 1 billion in 2008 [8]. Addressing high blood pressure worldwide is crucial. Approximately $30 \%$ of residents are affected in America and England and 19\% in Canada [9]. In Asia, high blood pressure has been reported as a risk factor in the region [10-12]. In Saudi Arabia, the prevalence of hypertension was $26.1 \%$ in crude terms. For males, the prevalence of hypertension was $28.6 \%$, while for females, the prevalence was significantly lower at $23.9 \%(\mathrm{p}<0.001)$ The urban population showed a significantly higher prevalence of hypertension at $27.9 \%$, compared to the rural population's prevalence of $22.4 \%$ [13].

In Saudi Arabia, a blood pressure survey was conducted in 1998 and recorded a blood pressure prevalence of only $16 \%$ [14]. In another survey in 2007 , the rate was $26 \%$, which was an increase in blood pressure in the Kingdom [13]. The percentage of hypertension in the Kingdom has been reported as $10 \%$ in Medina [15], $15 \%$ in the northern region [16], 2.4\% in Azir [17], 11\% in 
the southwest and 8.7-9.1\% in other regions [18]. In the Eastern Region, $32.7 \%$ of those with hypertension were men, and $13.5 \%$ were women $[19,20]$. Values were $22.6 \%$ in Jeddah [21], 30\% in Qasim [22], and 24.8\% in Arar [23]. Jeddah, Arar, Sharqiya and Qasim are among the areas with the highest prevalence of high blood pressure $[15,19,22,23]$. Many studies have confirmed that high blood pressure is more common among males than females, regardless of age [12,24]. In Saudi Arabia, more men are affected than women, as recorded by multiple studies in Qasim, Jeddah, Arar and the Eastern Region [19,20,22,23].

Obesity and overweight are among the most health-threatening diseases. In 2010, obesity caused 3 million deaths, and a statistical study from 1980 to 2013 showed an increase in BMI for adults, from $28 \%$ to $36.9 \%$ for men, $29.8 \%$ to $38 \%$ for women, $23.8 \%$ for boys, and $22.6 \%$ for girls [25]. Obesity was associated with many chronic diseases such as cardiovascular disease, especially in people with abdominal obesity [26-28]. This type of abdominal obesity is a major risk factor for high blood pressure [29,30]. Several studies have confirmed that high blood pressure increases with an increase in BMI [12,31-34]. In Saudi Arabia, some studies have recorded the same fact [20-22,35-37]. This was attributed to impairments in the aldosterone and the rennin-angiotensin system, which cause an elevation of sodium so that extracellular fluid leads to elevated blood pressure in the obese [38-40].

Many studies recommended lifestyle adjustments such as diet modification and increased physical activity to reduce blood pressure. It is well-accepted that weight loss of $5 \%$ reduced pressure by $7 \mathrm{mmHg}$ [41]. Additionally, exercise on a regular basis such as walking, swimming, and jogging for 30-45 minutes a day reduces blood pressure [42-44]. Vitamin D3 is produced in the skin by the conversion of 7-dehydrocholesterol after exposure to ultraviolet sunlight. In normal circumstances, the skin can supply the body $80 \%$ to $90 \%$ of its vitamin D requirements [45-47]. The remainder is obtained from the store of food or supplements $[47,48]$. The lack of vitamin $\mathrm{D}$ and its inadequacy have become a global health problem among children and adults over the past decade [4952]. Epidemiological studies have shown that individuals with severe vitamin D deficiency have a significantly higher risk of death due to dangerous diseases such as cardiovascular diseases, cancer, diabetes, dysfunction, infertility and miscarriage [53], but the intake of supplements at a dose of 2000-3000 IU reduced the mortality rate approximately 6\% [54-57]. Moreover, cancer rates could be reduced by approximately $25 \%$ [58]. In addition, vitamin D is essential for the health and safety of bone growth, the prevention of fragility and to maintain the natural balance between calcium and phosphorus [59-62].

Saudi Arabia has a common shortage of vitamin D among all age and sex groups [23,63-65], vitamin D deficiency, recorded as a percentage increase, reached $87 \%$ for Saudi men and $80 \%$ for women [63,66-68], and it is also common in children and teenagers/adolescents $[37,69,70]$. Moreover, among the Saudi population, vitamin D deficiency increased with age and is related to high BMI $[63,66,68,71]$. ALOthman et al. [71] and Elshafie et al. [72] reported that vitamin D increased with exercise in Saudi men through an increase in bone mass and calcium absorption and through increased fat metabolism, thus increasing the release of vitamin D stored in adipose tissues. Vitamin D deficiency and high blood pressure rank high among the world's most chronic diseases, and there is strong evidence that vitamin D plays an important role in hypertension [73-77]. The same result has been found in Saudi Arabia [78-79].

A study done in 2013 considered many reviews that included individuals with hypertension. They found that for every $10 \mathrm{mg} /$ $\mathrm{ml}$ increment in vitamin $\mathrm{D}$ levels, the danger of developing hypertension was lowered by $12 \%$. The general population with highest vitamin D levels had a 30\% lower chance of developing hypertension compared with those in the general population with the lowest levels of vitamin D. In any case, many of the reviews were done in the United States, implying that we cannot know without a doubt that outcomes would be the same in different countries [80].

This information informs our interest in finding the relationship between vitamin D status and blood pressure, BMI, physical activity, and nutritional status, in men and women younger or older than 40 years old in Saudi Arabia.

\section{Material and Methods}

\section{Participants}

A total of 55 adult patients (37 women and 18 men) were recruited from an outpatient clinic of King Khalid and King AbdulAziz Hospitals, Riyadh, Saudi Arabia. All participants were aged between 25-70 years old.

\section{Survey design}

A clear and consistent survey was designed by the researchers as a method of collecting study data. After completing the survey, testing and modifications were completed, according to the requirements for achieving the objectives of the study. The researcher filled out the survey while interviewing patients and the survey included the following points.

Extensive exercise during the week: According to the answered questionnaire, 20/55 participants used to play sports for 30 min daily, while 35/55 had not.

Demographic information: The age and sex of all participants were recorded.

Physical measurements: Immediately after completing the survey, the physical measurements were taken as follows.

Body mass index (BMI): Body mass index (BMI) was calculated from the following equation BMI=weight in kilograms/the square of the height in meters $\left(\mathrm{kg} \div \mathrm{m}^{2}\right)$, to determine the degree of obesity, where less than or equal to 18.5 is thin, between 18.5 and 24.9 is normal, between 25 to 29.9 is overweight, and greater than or equal to 30 is obese [81].

Weight: Weight was measured using an electronic balance and was recorded in $\mathrm{kg}$ to the nearest $0.1 \mathrm{~kg}$. 
Height: Height was measure during a ruler connected to the electronic scale used for weight and was recorded as $\mathrm{cm}$ to the nearest $0.1 \mathrm{~cm}$.

\section{Biochemical measurements}

Blood pressure: The diastolic and systolic blood pressure was measured after a 10-minute rest using a mercury blood pressure device (B.P., Monitor Mercurial, Riester, Germany). Blood pressure was categorized into normal and high, with normal considered to be less than or equal to 130 systolic and 85 diastolic and high set at 130 systolic and 85 diastolic or above, according to the method from [82].

Blood sampling: After an overnight fast, $10 \mathrm{ml}$ blood samples were collected and left to coagulate. The serum was separated and kept at -80\% until analysis. The level of 25-hydroxy vitamin D in serum was measured by Maglumi 1000 and Roche [82], Levels of 25-hydroxy vitamin $\mathrm{D}$ are normal if the range is between 75 and $250 \mathrm{nmol} / \mathrm{L}$; values less than $25 \mathrm{nmol} / \mathrm{L}$ are considered deficiency, and values above the $25-75 \mathrm{nmol} / \mathrm{L}$ range are considered insufficient.

\section{Results and Discussion}

Data from the current study are presented in the following Table 1 and Figure 1 show the average age and vitamin D intake in the studied participants. Spearman correlations between vitamin D status and BMI, age, blood pressure, sex, and physical activities were performed. Moreover, the relationship between physical activities and blood pressure was presented. Logistic regression using vitamin D as a dependent variable is also presented. It is well-accepted that overweight or obese individuals of both sexes demonstrate high risk of hypertension as a component of metabolic syndrome (MetS), especially in the case of vitamin D deficiency [8284].

Table 1: Average age and vitamin $\mathrm{D}$ in the three cases (normal/ insufficient/ deficiency).

\begin{tabular}{|c|c|c|c|c|}
\hline Groups & Count & Sum & Average & Variance \\
\hline normal & 3 & 253.5 & 84.5 & 160.75 \\
\hline insufficient & 11 & 449.05 & 40.82 & 192.2 \\
\hline deficiency & 41 & 892.83 & 21.78 & 51.53 \\
\hline
\end{tabular}

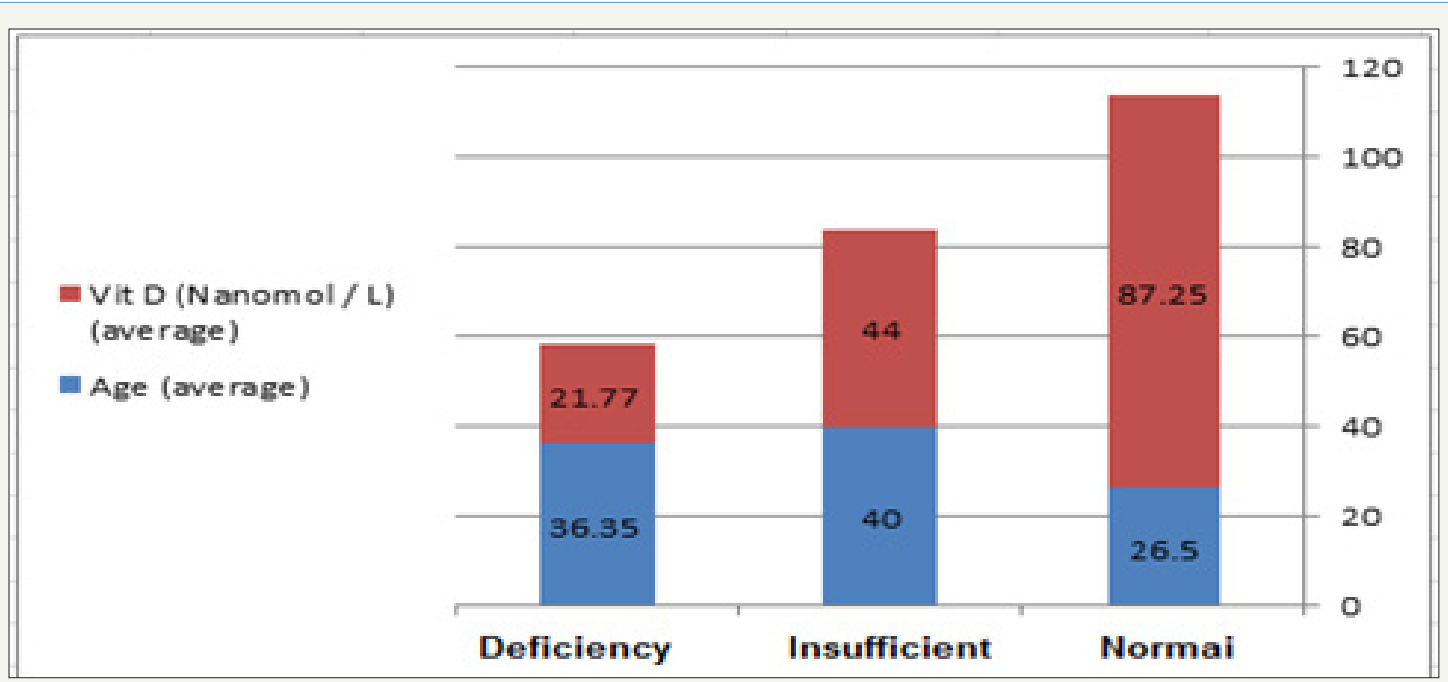

Figure 1:

Table 2: Spearman correlations between vitamin D status and age of the participants presented as either $>0 R<40$ years old.

\begin{tabular}{|c|c|c|c|}
\hline \multirow{2}{*}{ Age Groups } & Parameters & R(Spearman Correlation) & P Value \\
\hline \multirow{3}{*}{$<40$ years } & Vit. D (Nanomol/L) with BMI (Number) & 0.070 & 0.693 \\
\cline { 2 - 4 } & Vit. D (Nanomol/L) with Age & 0.165 & 0.350 \\
\cline { 2 - 4 } & Vit. D (Nanomol/L) with Systolic pressure & 0.080 & 0.651 \\
\cline { 2 - 4 } & Vit. D (Nanomol/L) with Diastolic pressure & 0.105 & $\mathrm{P}^{\mathrm{a}}$ \\
\hline
\end{tabular}




\begin{tabular}{|c|c|c|c|c|}
\hline \multirow{4}{*}{$>40$ years } & Vit. D (Nanomol/L) with BMI (Number) & $-0.536^{*}$ & 0.012 & $\mathrm{~N}^{\mathrm{b}}$ \\
\hline & Vit. D (Nanomol/L) with Age & 0.075 & 0.746 & $\mathrm{P}^{\mathrm{a}}$ \\
\hline & Vit. D (Nanomol/L) with Systolic pressure & 0.139 & 0.548 & $\mathrm{P}^{\mathrm{a}}$ \\
\hline & Vit. D (Nanomol/L) with Diastolic pressure & 0.183 & 0.428 & $\mathrm{P}^{\mathrm{a}}$ \\
\hline
\end{tabular}

${ }^{*}$ Correlation is significant at the 0.05 level.

aPositive Correlation/ b Negative Correlation.

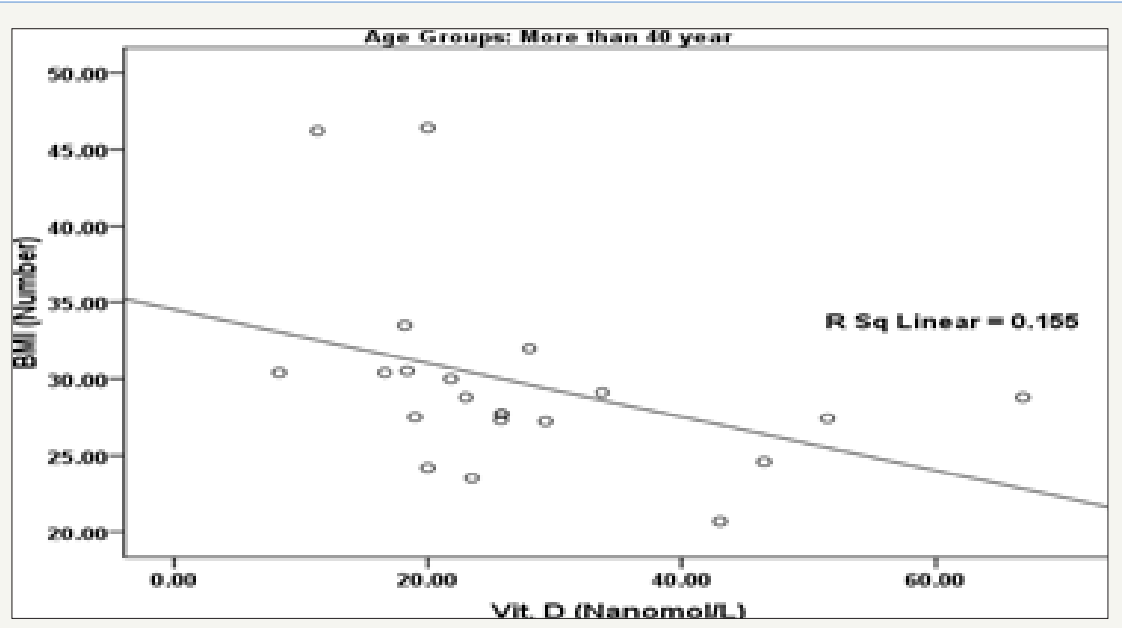

Figure 2: Correlation between Vit. D (Nanomol/L) and BMI (Number) with best fit line curve (Negative correlation) in Age group (More than 40 year).

Table 3: Crosstabs demonstrates the relationship between vitamin D status and blood pressure in the two studied age groups.

\begin{tabular}{|c|c|c|c|c|c|c|}
\hline \multirow[b]{2}{*}{ Age Groups } & & & \multicolumn{3}{|c|}{ Vit. D (Describe) } & \multirow[b]{2}{*}{$P$ Value } \\
\hline & \multicolumn{2}{|c|}{$\begin{array}{c}\text { Blood Pressure } \\
\text { Normal }\end{array}$} & Insufficient & Deficiency & & \\
\hline \multirow{4}{*}{$<40$ years } & & $\mathrm{N}$ & 3 & 5 & 14 & \multirow{4}{*}{0.160} \\
\hline & Normal & $\%$ & $100.00 \%$ & $45.50 \%$ & $70.00 \%$ & \\
\hline & \multirow[b]{2}{*}{ High } & $\mathrm{N}$ & 0 & 6 & 6 & \\
\hline & & $\%$ & $0.00 \%$ & $54.50 \%$ & $30.00 \%$ & \\
\hline \multirow{4}{*}{$>40$ years } & \multirow[b]{2}{*}{ Normal } & $\mathrm{N}$ & 0 & 3 & 4 & \multirow{4}{*}{1.000} \\
\hline & & $\%$ & $0.00 \%$ & $30.00 \%$ & $36.40 \%$ & \\
\hline & \multirow[b]{2}{*}{ High } & $\mathrm{N}$ & 0 & 7 & 7 & \\
\hline & & $\%$ & $0.00 \%$ & $70.00 \%$ & $63.60 \%$ & \\
\hline
\end{tabular}

The obtained data presented in Table 2 and Figure 2 D deficiency had higher risks for MetS, hypertriglyceridemia and demonstrate the significant negative correlation of vitamin $\mathrm{D}$ deficiency and BMI in participants aged more than 40 years but not in younger subjects. This finding is supported by the recent work of [85], which reported an inverse relationship between vitamin D level and higher prevalence of BMI as one of the metabolic syndrome phenotypes. They reported that women with vitamin low HDL, all risk factors of hypertension, than those with adequate levels. Table 3 describes Chi-Square Test to compare between the expected and the observed numbers in Vit. D (Describe) groups with Blood pressure groups for each Age group.

Hypertension usually developed when the balance between vasodilation and vasoconstriction is shifted towards 
vasoconstriction. This balance is also controlled by epigenetic factors, among which are vitamin D deficiencies [86]. When there is an unstable balance, vitamin D deficiency triggers a shift toward vasoconstriction. Table 3 and Figure 3(A\&B) shows the association between vitamin $\mathrm{D}$ deficiency and hypertension. While only $30 \%$ of vitamin D-deficient participants aged $<40$ years were hypertensive, more than $60 \%$ (63.60) of participants aged $>40$ years were, demonstrating that hypertension correlated with vitamin D deficiency. Our data are supported by previous studies that hypothesized an inverse relationship between vitamin D serum level and blood pressure $[87,88]$. This is in good agreement with the many previous studies reporting that vitamin D supplementation for 6 weeks to 1 year raised 25(OH)D levels and had a minimal effect on blood pressure in non motensive cohorts that included almost $30 \%$ of hypertensive subjects aged $<40[86,89,90]$. Table 4 describes Chi-Square Test to compare between the expected and the observed numbers in Vit. D (Describe) groups with Blood pressure groups for each Sex group.

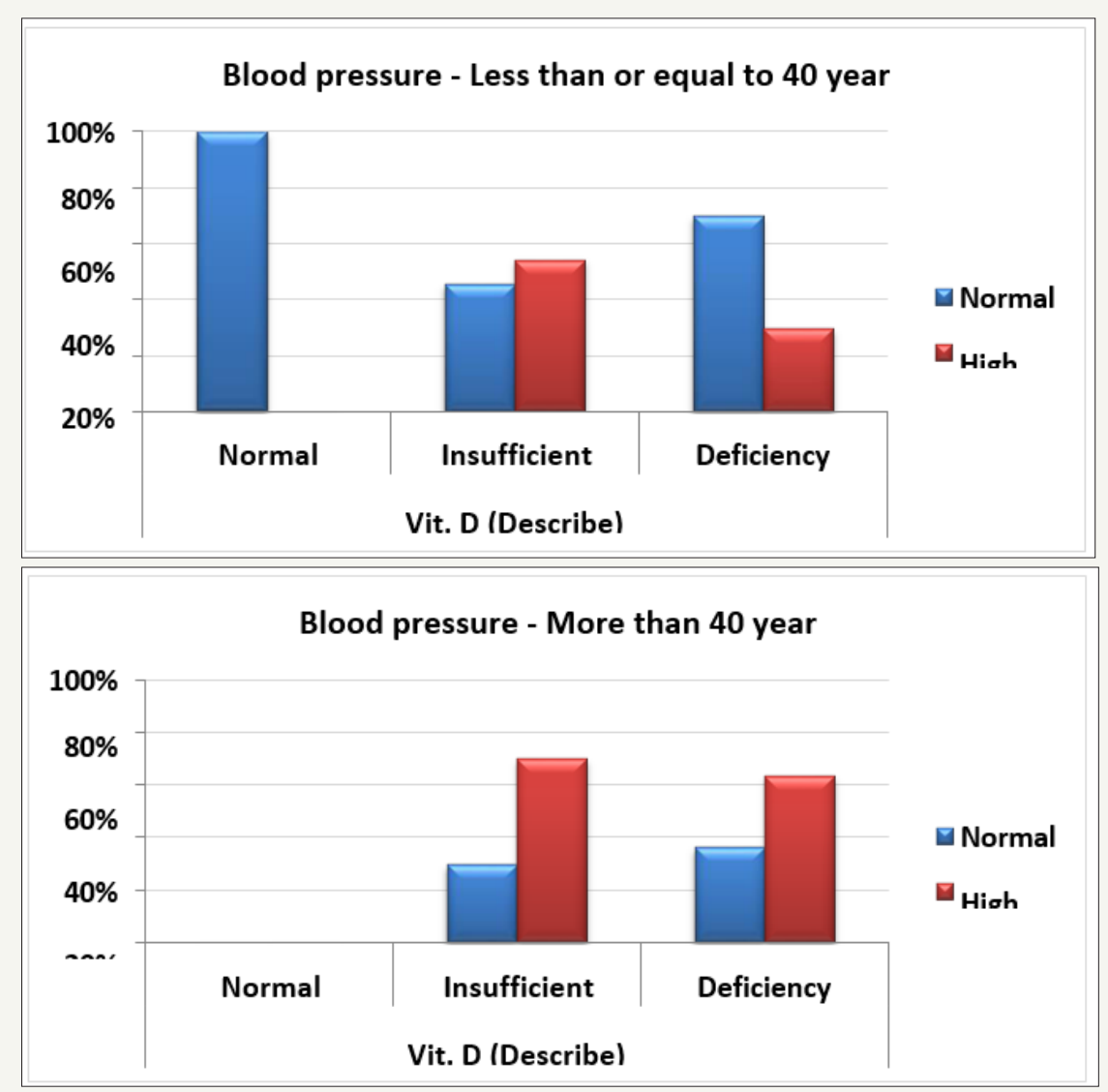

Figure 3 (A\&B): Percentage distribution of normal and high blood pressure participants in relation to Vit. D status in all participants within the two studied groups with $(<40 \mathrm{Up}$, and $>40$ down).

Table 4: Crosstabs (sex groups).

\begin{tabular}{|c|c|c|c|c|c|c|}
\hline \multirow[b]{2}{*}{ Sex } & & & \multicolumn{3}{|c|}{ Vit. D (Describe) } & \multirow[b]{2}{*}{$P$ Value } \\
\hline & \multicolumn{2}{|c|}{$\begin{array}{c}\text { Blood Pressure } \\
\text { Normal }\end{array}$} & Insufficient & Deficiency & & \\
\hline \multirow{4}{*}{ Male } & & $\mathrm{N}$ & 0 & 5 & 1 & \multirow{4}{*}{0.615} \\
\hline & Normal & $\%$ & $0.00 \%$ & $38.50 \%$ & $20.00 \%$ & \\
\hline & \multirow[b]{2}{*}{ High } & $\mathrm{N}$ & 0 & 8 & 4 & \\
\hline & & $\%$ & $0.00 \%$ & $61.50 \%$ & $80.00 \%$ & \\
\hline
\end{tabular}




\begin{tabular}{|c|c|c|c|c|c|}
\hline \multirow{3}{*}{ Female } & \multirow{3}{*}{ Normal } & $\mathrm{N}$ & 3 & 3 & 17 \\
\cline { 2 - 6 } & & $\%$ & $100.00 \%$ & $37.50 \%$ & $65.40 \%$ \\
& \multirow{3}{*}{ High } & $\mathrm{N}$ & 0 & 5 & 9 \\
\cline { 2 - 6 } & & $\%$ & $0.00 \%$ & $62.50 \%$ & $34.60 \%$ \\
\hline
\end{tabular}

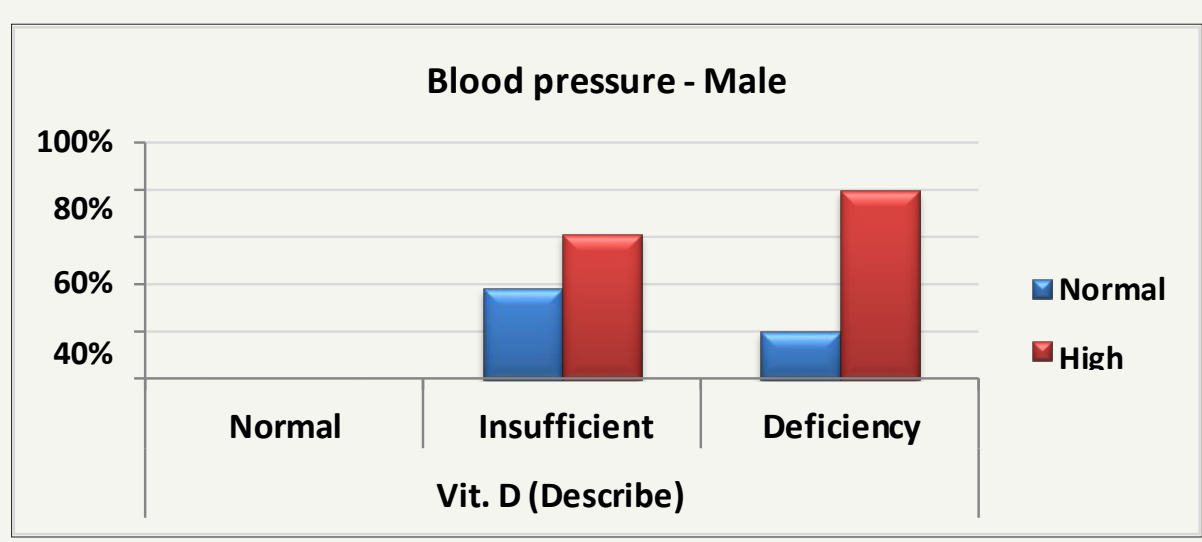

Figure 4A: Distribution of Vit. D (Describe) groups with Blood pressure groups in Sex group (Male).

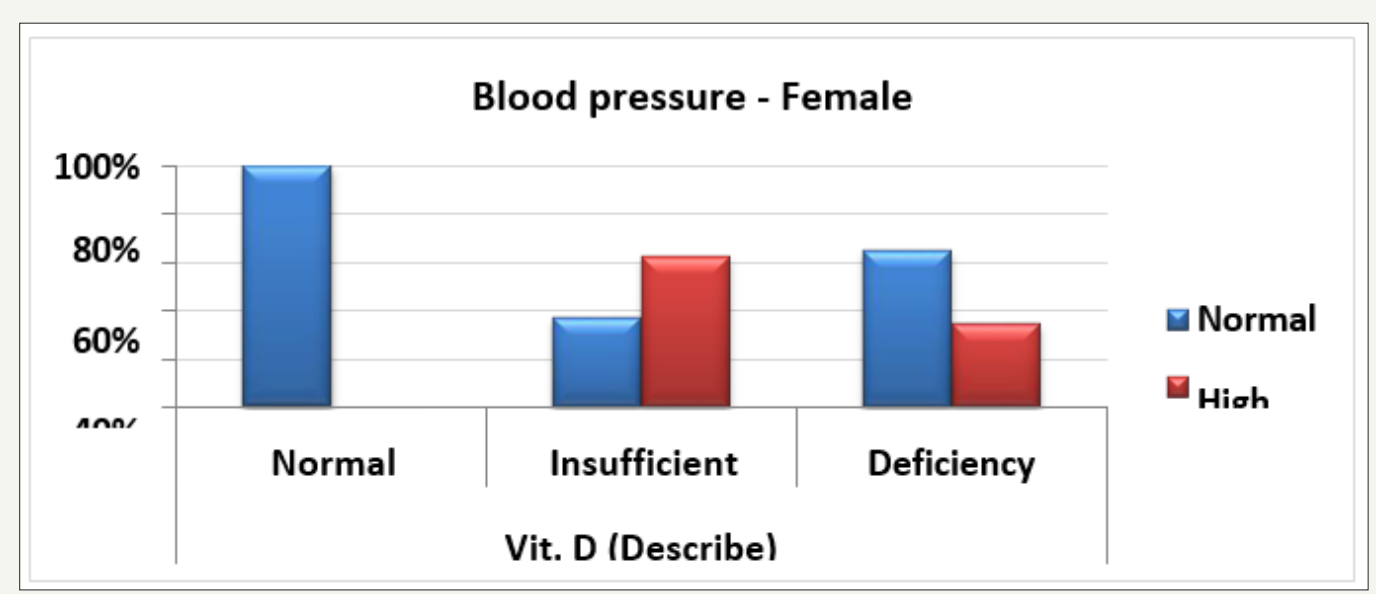

Figure 4B: Distribution of Vit. D (Describe) groups with Blood pressure groups in Sex group (Female).

Moreover, our data demonstrate the remarkable effect of vitamin D deficiency on blood pressure in males compared with females Table 4 and Figure 4(A\&B). This finding gain support from the key observation that reported the sex-specific differences in proteins associated with lipid, testosterone metabolism, coagulation, and vitamin D signaling. Compared to females, males have remarkably higher levels of these proteins, which might render them more susceptible to demonstrating vitamin $\mathrm{D}$ deficiency-related complications, among which is high blood pressure [91]. It is welldocumented that vitamin D insufficiency/deficiency is a major public health problem observed in all age groups. In relation to physical activity, vitamin D deficiency is associated with a decrease in neuromuscular function including muscular strength, walking speed, and aerobic capacity [92]. Table 5 describes Chi-Square Test to compare between the expected and the observed numbers in Vit. D (Describe) groups with Play port about 30 minutes groups for each Age group
Table 5 and Figure 5(A\&B) demonstrate the relationship between vitamin D status and physical activities in the two studied age groups. It can easily be noticed that vitamin D deficiency was accompanied by a remarkable but non-significant relationship with the absence of physical activity in $81.80 \%$ of the older aged group ( $>40$ years) compared to only $60.00 \%$ in the younger group ( $<40$ years). Within each group, it can be suggested that physical performance is of more critical importance to older people than to the young. This finding is supported in the previous work of [93], which shows that vitamin D deficient and insufficient individuals had poorer physical performance compared to those with a normal vitamin D status. The inability of older participants to perform any daily exercise can be attributed to multiple mechanisms related to vitamin D deficiency. First, vitamin D affects several aspects of vascular integrity, including arterial stiffness and heart muscle function, which are important components of aerobic and anaerobic exercise and recommended as daily physical activities, 
especially for those older than 40 years of age [94]. Second, the effect of vitamin D on major brain functions such as gabaergic tone, serotonin and dopamine levels is collectively needed for efficient muscle coordination and avoidance of central fatigue [95]. A high ratio of serotonin to dopamine affects exercise performance because of its effect on the general feeling of tiredness and the perceptions of effort $[96,97]$. Table 6 describes Chi-Square Test to compare between the expected and the observed numbers in Blood pressure groups with Play port about 30 minutes groups for each sex group with Odd Ratio and (95\%CI).
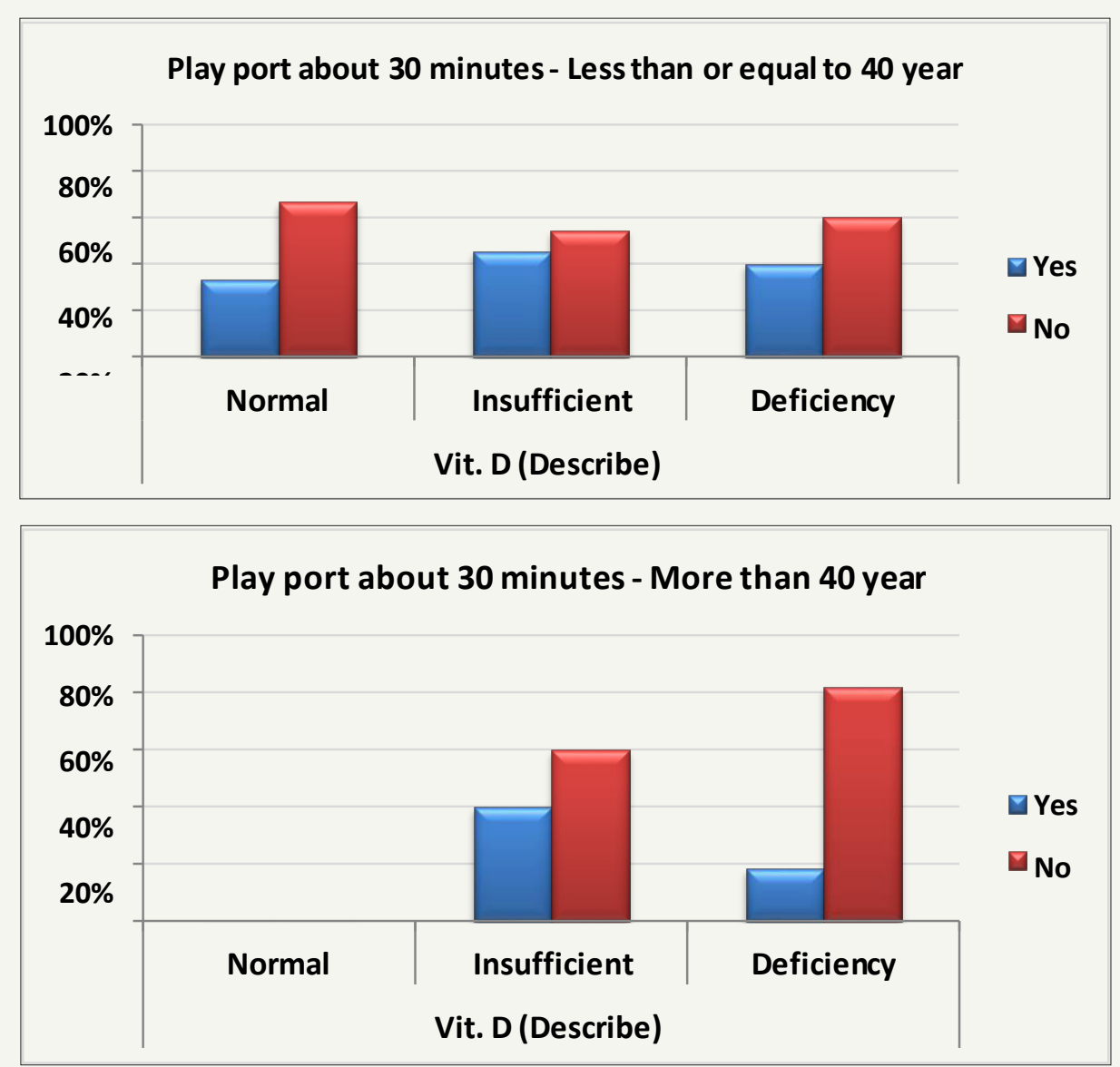

Figure 5 (A\&B): Percentage distribution of performance of physical activities in all participants in relation to Vit. D status within the two studied groups with ( $<40 \mathrm{Up}$, and $>40$ down).

Table 5: Crosstabs demonstrates the relationship between vitamin D status and performance of physical activities in the two studied age groups.

\begin{tabular}{|c|c|c|c|c|c|c|}
\hline \multirow[b]{2}{*}{ Age Groups } & \multirow{2}{*}{\multicolumn{2}{|c|}{$\begin{array}{c}\text { Play Port about } 30 \text { Minutes } \\
\text { Normal }\end{array}$}} & \multicolumn{3}{|c|}{ Vit. D (Describe) } & \multirow[b]{2}{*}{ P Value } \\
\hline & & & Insufficient & Deficiency & & \\
\hline \multirow{4}{*}{$<40$ years } & \multirow[b]{4}{*}{ No } & $\mathrm{N}$ & 1 & 5 & 8 & \multirow{4}{*}{0.918} \\
\hline & & $\%$ & $33.30 \%$ & $45.50 \%$ & $40.00 \%$ & \\
\hline & & $\mathrm{N}$ & 2 & 6 & 12 & \\
\hline & & $\%$ & $66.70 \%$ & $54.50 \%$ & $60.00 \%$ & \\
\hline \multirow{4}{*}{$>40$ years } & \multirow[b]{2}{*}{ Yes } & $\mathrm{N}$ & 0 & 4 & 2 & \multirow{4}{*}{0.361} \\
\hline & & $\%$ & $0.00 \%$ & $40.00 \%$ & $18.20 \%$ & \\
\hline & \multirow[b]{2}{*}{ No } & $\mathrm{N}$ & 0 & 6 & 9 & \\
\hline & & $\%$ & $0.00 \%$ & $60.00 \%$ & $81.80 \%$ & \\
\hline
\end{tabular}


Table 6 demonstrates the relationship between exercise and blood pressure improvement in males and females. It can easily be observed that males were more responsive to exercise in terms of improvements in hypertension compared with those who were not playing sports for half an hour daily. This can find support in the recent work of [81], who concluded that overall physical activity is effective in modulating blood pressure Figure 6.

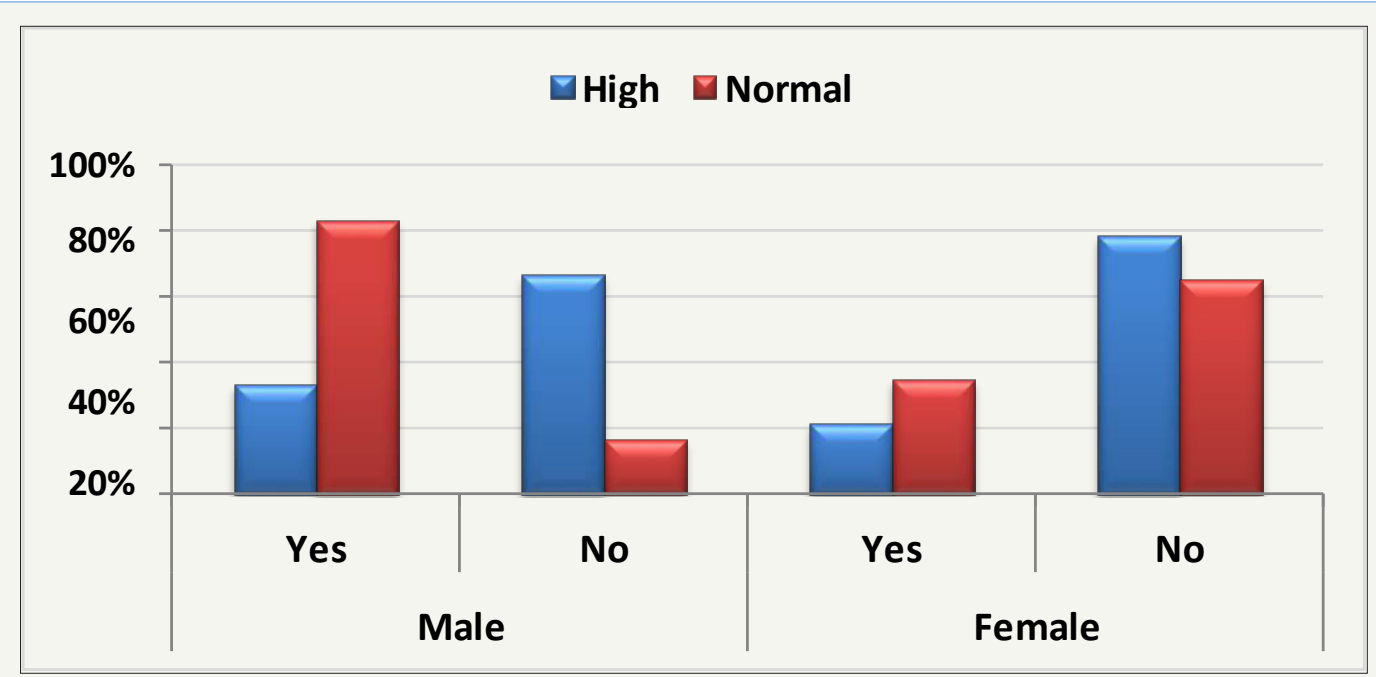

Figure 6: Distribution of blood pressure groups with Play port about 30 minutes groups in both sex groups (male and female).

Table 6: Crosstabs (sex groups).

\begin{tabular}{|c|c|c|c|c|c|c|}
\hline \multirow[b]{2}{*}{ Sex } & \multirow{2}{*}{\multicolumn{2}{|c|}{$\begin{array}{c}\text { Play Port about } 30 \text { Minutes } \\
\text { High }\end{array}$}} & \multicolumn{2}{|c|}{ Blood Pressure } & \multirow[b]{2}{*}{ P Value } & \multirow{2}{*}{ Odd Ratio $(95 \% \mathrm{CI})$} \\
\hline & & & \multirow{2}{*}{$\begin{array}{c}\text { Normal } \\
4\end{array}$} & \multirow[b]{2}{*}{5} & & \\
\hline \multirow{4}{*}{ Male } & \multirow[b]{4}{*}{ No } & $\mathrm{N}$ & & & \multirow{4}{*}{0.046} & \multirow{4}{*}{$\begin{array}{c}0.100 \\
(0.009-1.170)\end{array}$} \\
\hline & & $\%$ & $33.30 \%$ & $83.30 \%$ & & \\
\hline & & $\mathrm{N}$ & 8 & 1 & & \\
\hline & & $\%$ & $66.70 \%$ & $16.70 \%$ & & \\
\hline \multirow{4}{*}{ Female } & & $\mathrm{N}$ & 3 & 8 & \multirow{4}{*}{0.477} & \multirow{4}{*}{$\begin{array}{c}0.511 \\
(0.110-2.381)\end{array}$} \\
\hline & Yes & $\%$ & $21.40 \%$ & $34.80 \%$ & & \\
\hline & & $\mathrm{N}$ & 11 & 15 & & \\
\hline & No & $\%$ & $78.60 \%$ & $65.20 \%$ & & \\
\hline
\end{tabular}

Table 7: Logistic regression using vitamin D status as dependent variable.

\begin{tabular}{|c|c|c|c|c|c|c|c|}
\hline & & Regression & \multirow{2}{*}{ Standard Error } & & \multicolumn{2}{|c|}{ 95\% CI for Odds Ratio } \\
\cline { 5 - 7 } Age Groups & Parameters & Coefficient & & Odds Ratio & Lower & Upper & P Value \\
\hline More than 40 years & Sex & 3.701 & 1.312 & 40.500 & 3.093 & 530.319 & 0.005 \\
\hline
\end{tabular}

Table 7 describes Logistic Regression Test for Vit. D (Describe) as dependent variable with groups (Deficiency (1) and Normal -Insufficient (0), with (BMI (Number), Age, Sex, Systolic pressure, Diastolic pressure, Blood pressure and Play port about 30 minutes) as independent variables using Stepwise method for each Age group. In logistic regression, the odds ratios obtained usually describe the associations of biomarkers with specific clinical events. Table 7 demonstrates the logistic regression of the obtained data using vitamin D status as the clinical event, i.e., as a dependent variable. It can be easily observed that sex greatly contributes in the susceptibility to develop hypertension in older participants $(>40$ years) in the case of vitamin D deficiency (odds ratio of 40.500). In relation to Table 3, it can easily be observed that males are more affected than females by vitamin D deficiency. While the reported correlation between vitamin D deficiency and age was in good agreement with multiple previous studies $[87,88]$, the recorded susceptibility of males to having higher blood pressure than females (Table 4) and (Figure 4A\&B), is contradicted by Gagnon et 
al. [98], who reported that older females with vitamin D deficiency are more susceptible to developing hypertension than males.

\section{Conclusion}

In this study highlighted the relationship between vitamin D deficiency and hypertension in older Saudi males, as well as the relationship with higher BMI and lower physical activity. Thus, supplementation with vitamin $\mathrm{D}$ and encouragement to partake in physical activities can be used as a preventive strategy in the Saudi population with common and repeatedly reported impaired vitamin D status (deficiency/insufficiency). However, despite the accumulating evidence of a consistent link between vitamin $\mathrm{D}$ and blood pressure, more studies are needed to ascertain the effectiveness of vitamin D supplementation as a treatment strategy.

\section{Acknowledgement}

This research project was supported by a grant from the Research Center of the Center for Female Scientific and Medical Colleges at King Saud University.

\section{Conflict of Interest}

The authors declare no potential conflicts of interest with respect to the authorship, and/or publication of this article.

\section{References}

1. Organization WH(2008) Causes of death. World Health Organization, Geneva, Switzerland.

2. LimSS, Vos T, Flaxman AD, Danaei G, Shibuya K,et al.(2012) A comparative risk assessment of burden of disease and injury attributable to 67 risk factors and risk factor clusters in 21 regions, 1990-2010: a systematic analysis for the Global Burden of Disease Study 2010.Lancet380(9859): 2224-2260.

3. Kim MJ, Lim NK, Park HY(2012) Relationship between prehypertension and chronic kidney disease in middle-aged people in Korea: the Korean genome and epidemiology study. BMC public health12(1): 960.

4. Okuda T, Okamura K, Shirai K, Urata H(2018) Effect of angiotensin-converting enzyme inhibitor/calcium antagonist combination therapy on renal function in hypertensive patients with chronic kidney disease: chikushi anti-hypertension trial-benidipine and perindopril. J Clin Med Res 10(2):117.

5. Organization WH(2015) World health statistics. World HealthOrganization, Geneva, Switzerland.

6. EttehadD, Connor AE,Kiran A, Anderson SG, Callender T, et al. (2016) Bloodpressureloweringforpreventionofcardiovasculardiseaseanddeath:a systematic review and meta-analysis. Lancet 387(10022): 957967.

7. Harsha DW, BrayGA, (2017) Diet and Blood Pressure: The high and low of it, in nutrition guide for physicians and related healthcare professionals. Springer, pp. 123-128.

8. OrganizationWH (2011) Global status report on noncommunicable diseases 2010. World HealthOrganization, Geneva, Switzerland.

9. JoffresM,Emanuela F, Cathleen G, Cynthia R,Fleetwood L, etal.(2013) Hypertensionprevalence, awareness, treatmentandcontrolin National surveys from England, the USA and Canada, and correlation with stroke and ischaemic heart disease mortality: a cross-sectional study. BMJ open3(8): e003423.

10. Zhou B, Bentham J, Di Cesare M, Bixby H, Danaei G, et al. (2017) Worldwide trends in blood pressure from 1975 to 2015: a pooled analysis of
1479 population-based measurement studies with $19 \cdot 1$ million participants. Lancet 389(10064):37-55.

11. Lim SS, Vos T, Flaxman AD, Danaei G, Shibuya K, et al.(2013) A comparative risk assessment of burden of disease and injury attributable to 67 risk factors and risk factor clusters in 21 regions, 1990-2010: a systematic analysis for the Global Burden of Disease Study 2010. Lancet380(9859): 2224-2260.

12. Kishore J,Neeru G, Charu K, Neeta K(2016) Prevalence of hypertension and determination of its risk factors in rural Delhi. International Journal of hypertension

13. AlNozha MM, Abdullah M, Arafah MR, Khalil MZ, Khan NB, et al.(2007) Hypertension in Saudi Arabia. Saudi Med J (1):77-84.

14. ElHazmiA, Warsy AS, Al Swailem AR, Al Swailem AM (1998) Prevalence of hypertension in adult Saudi population. Saudi Medical Journal19(2): 117-122.

15. AhmedAF,Mahmoud ME(1992)TheprevalenceofhypertensioninSaudiArabia.Saudi Medical Journal13(6): 548-551.

16. Nazim Uddin K (1994) Prevalence of hypertension in Saudi Arabia. Practitioner East Mediterr11:805-806.

17. Mahfouz AA,AlErianRA(1993)Prehypertension in Asir region, southwestern Saudi Arabia: Southeast Asian J Trop Med Public Health 24(2):284-286

18. AlNozha MM, Ali MS,OsmanAK(1997) Arterial hypertension in Saudi Arabia. Ann Saudi Med17(2):170-174.

19. Sabra AA, Taha AZ, AlSebiany AM, AlKurashi NY, AlZubier AG(2007) Coronary heart disease risk factors: prevalence and behavior among male university students in Dammam City, Saudi Arabia. J Egypt Public Health Assoc 82(1-2):21-42.

20. Koura M, Al Dabal BK, Rasheed P, Al Sowielem LS, Makki SM (2012) Prehypertension among young adult females in Dammam, Saudi Arabia. East Mediterr Health J 18(7): 728-734

21. Elkhalifa AM, Kinsara AJ, Almadani DA(2011) Prevalence of hypertension in a population of healthy individuals. Med PrincPract20(2):152-155.

22. KalantanKA,Mohamed AG, AlTaweel AA, Abdul Ghani HM (2001) Hypertensionamongattendantsofprimaryhealthcarecentersin Al-Qassim region, Saudi Arabia. Saudi Med J 22(11):960-963

23. ElFetoh NMA (2017)Vitamin D deficiency and risk of diabetes mellitus in arar, kingdom of SaudiArabia: A cross sectional study. European Journal of Research in Medical Sciences 5(1).

24. Ferguson TS, Younger NO, TullochReid MK, Wright MB, Ward EM, et al.(2008) Prevalence of prehypertension and its relationship to risk factors for cardiovascular disease in Jamaica: analysis from a cross-sectional survey. BMC Cardiovasc Disord28:20.

25. Ng M, Fleming T, Robinson M, Thomson B, Graetz N, et al. (2014) Global, regional, and national prevalence of overweight and obesity in children and adults during 1980-2013: a systematic analysis for the Global Burden of Disease Study 2013. Lancet384(9945): 766-781.

26. Yusuf S, Hawken S, Ounpuu S, Dans T, Avezum A, etal. (2004)Effectofpotentiallymodifiablerisk factorsassociatedwithmyocardial infarction in 52 countries (the INTERHEART study): case-control study. Lancet364(9438):937-952.

27. Goodfriend TL, CalhounDA(2004) Resistant hypertension, obesity, sleep apnea, and aldosterone. Hypertension 43(3): 518-524.

28. Pozza C,Isidori AM (2018) What's behind the obesity epidemic, in imaging in bariatric surgery. Springer, pp.1-8.

29. Thompson D,Edelsberg J, Colditz GA, Bird AP, Oster G(1999) Lifetimehealthandeconomicconsequencesofobesity. Arch Intern Med159(18): 2177-2183. 
30. Freedman DS, Khan LK, Serdula MK, Galuska DA, Dietz WH (2000) Trends and correlates of class 3 obesity in the United States from 1990 through 2000. Jama 288(14): 1758-1761.

31. Gupta R,Guptha S, Gupta VP, Prakash H (1995) Prevalence and determinants of hypertension in the urban population of Jaipur in western India. J Hypertens13(10):1193-1200.

32. Grotto I, Ehud G, Michael H, Yehonatan S (2006) Prevalence ofprehypertension and associated cardiovascular risk profiles among young Israeli adults. Hypertension 48(2): 254-259.

33. ReddySS, PrabhuG (2005) Prevalence and risk factors of hypertension in adults in an Urban Slum, Tirupati, AP. Indian Journal of community medicine 30(3): 84-86

34. Kawamoto R, Ohtsuka N, Ninomiya D, Nakamura SR (2008) Association of obesity and visceral fat distribution with intima-media thickness of carotid arteries in middle-aged and older persons. Intern Med 47(3): 143-149.

35. AlAsmary SM, AlShehri AA, Farahat FM, AbdelFattah MM, AlShahran MM, et al.(2008) Community-based screening forpre-hypertensionamongmilitary active duty personnel. Saudi Med J 29(12): 1779-1784.

36. AlMohaissen MA, AlObaid QY, AlGhamdi WA, AlAlyani HS, DahmanSM, etal. (2017) Prevalence and determinants of hypertensionandhighnormal blood pressure among young adult Saudi females.Fam Community Health 40(3):221-230.

37. AlAgha AE,Mahjoub AO(2018) Impact of body mass index on high blood pressure among obese children in the western region of Saudi Arabia. Saudi Med J39(1): 45-51.

38. Hall JE (1997) Mechanisms of abnormal renal sodium handling in obesityhypertension. Am J Hypertens 10(S4): 49S-55S.

39. EngeliS,Schling P, Gorzelniak K, Boschmann M, Janke J,et al.(2003) The adipose-tissue renin-angiotensin-aldosterone system: role in the metabolic syndrome. Int J Biochem Cell Biol 35(6): 807-825.

40. Rahmouni K, Marcelo Correia LG, William G,Haynes G, Allyn LM (2005) Obesity-associated hypertension. Hypertension, 45(1): 9-14.

41. Engeli S,Böhnke J, Gorzelniak K, Janke J, Schling P, et al. (2005) Weight loss and the renin-angiotensin-aldosteronesystem.Hypertension45(3):356-362.

42. Cornelissen VA,FagardRH(2005) Effects of endurance training on blood pressure, blood pressure-regulating mechanisms and cardiovascular risk factors. Hypertension46(4): 667-675.

43. Cornelissen VA, SmartNA (2013) Exercise training for blood pressure: a systematic review and meta-analysis. J Am Heart Assoc12(1):e004473

44. Landram MJ,Utter AC,Baldari C, Guidetti L,Anulty SR, et al. (2018) Differential effects of continuous versus discontinuous aerobic training on blood pressure and hemodynamics. J Strength Cond Res 32(1):97-104.

45. Webb AR,Kline L,Holick MF (1988) Influenceofseasonandlatitude on the cutaneoussynthesis of vitamin D3: exposure to winter sunlight in Boston and Edmonton will not promote vitamin D3 synthesis in human skin J Clin Endocrinol Metab67(2):373-378.

46. HolickMF(1996) Photobiology, metabolism, mechanism of action, and clinicalapplications. Primer on the metabolic bone diseasesand disorders of bone mineral metabolism.

47. Holick MF(2004) Sunlight and vitamin D for bone health and prevention of autoimmune diseases, cancers, and cardiovascular disease. Am J Clin Nutr80(6): 1678S-1688S.

48. Holick MF, ChenTC(2008) Vitamin D deficiency: a worldwide problem with health consequences. Am J Clin Nutr87(4): 1080S-1086S

49. Hashemipour S,Larijani B, Adibi H, Javadi E, Sedaghat M, et al.(2004) Vitamin D deficiency and causative factors in the population of Tehran BMC Public health 4(1): 38.
50. BatiehaA, Khader Y, Jaddou H, Hyassat D, Batieha Z, et al. (2011) Vitamin D status in Jordan: dress style and genderdiscrepanciesAnn NutrMetab58(1):10-18

51. Brüggmann D,Alafi A, Jaque J, Klingelhöfer D, Bendels MH, et al.(2018) World-wide research architecture of vitamin D research: density-equalizing mapping studies and socio-economic analysis. Nutr J 17(1): 3.

52. Wang EW,Pang MY, Siu PM, Lai CK, Woo J, etal.(2018) VitaminDstatusandcardiometabolicriskfactorsinyoungadultin Hong Kong: associations and implications. Asia Pac J Clin Nutr27(1): 231.

53. Pludowski P,Holick MF, Pilz S, Wagner CL, Hollis BW, et al. (2013) Vitamin D effects on musculoskeletal health, immunity, autoimmunity, cardiovascular disease, cancer, fertility, pregnancy, dementia and mortality-a review of recent evidence. Autoimmun Rev 12(10):976-989.

54. Bjelakovic G,Gluud LL, Nikolova D, Whitfield K, Wetterslev J,et al.(2011) Vitamin D supplementation for prevention of mortality inadults.Cochrane Database Syst Rev 7(7)

55. AutierBM, Pizot C, Mullie P (2014) Vitamin D status and ill health: a systematic review. Lancet Diabetes Endocrinol 2(1): 76-89.

56. Shepherd L,SouberbielleJC, Bastard JP, Fellahi S, Capeau J, et al.(2014) Prognostic value of vitamin D level for all-cause mortality and association with inflammatory markers, in HIV-infected persons. J Infect Dis 210(2): 234-243.

57. Al Daghri N (2017) Efficacy of various Vitamin D correction strategies in Saudi adults and children. The FASEB Journal31(1 Supplement): 638.5638.5 .

58. Grant WB(2010) An ecological study of cancer incidence and mortality rates in France with respect to latitude, an index for vitamin D production. Dermatoendocrinol 2(2):62-67.

59. Reid IR, Bolland MJ, Grey A(2014) Effects of vitamin D supplements on bone mineral density: a systematic review and meta-analysis. Lancet 383(9912):146-155.

60. GiolloA,Idolazzi L, Caimmi C, Fassio A, Bertoldo F, etal.(2017)VitaminDlevelsstronglyinfluencebonemineraldensityandbone turnover markers during weight gain in female patients with anorexia nervosa. Int J Eat Disord 50(9):1041-1049

61. Bischoff Ferrari HA, Sadler MJ(2018)Authorised EU health claim for vitamin D and reducedriskof falls inFoods,NutrientsandFoodIngredientswith authorized EUHealth Claims, Elsevier, pp. 49-63.

62. AlDaghri NM, Yousef Al S, Naji A, Riad S, Alfawaz H, et al.(2017) Vitamin D status correction in Saudi Arabia: an experts' consensusundertheauspicesoftheEuropeanSocietyforClinicalandEconomicAspectsof Osteoporosis, Osteoarthritis, and Musculoskeletal Diseases (ESCEO). Arch Osteoporos12(1): 1 .

63. Ardawi MS, Sibiany AM, Bakhsh TM, Qari MH, Maimani AA(2012) High prevalence of vitamin D deficiency among healthy Saudi Arabianmen:relationshiptobonemineraldensity, parathyroidhormone,boneturnover markers, and lifestyle factors.OsteoporosInt23(2): 675-686.

64. Al Alyani H, Haifa A AlT, Omar N AlE, Fawaz MA, SadatAli M(2018)Vitamin D deficiency in Saudi Arabians: A reality or simply hype: A meta-analysis.J Family Community Med25(1):1

65. AljefreeNM,Lee P, Ahmed F, (2017) Knowledge and attitudes about vitamin D, and behaviorsrelatedtovitaminDinadultswithandwithoutcoronaryheartdiseaseinSaudi Arabia. BMC public health 17(1): 266.

66. Ardawi MS,Qari MH, Rouzi AA, Maimani AA, Raddadi RM(2011)VitaminDstatusin relationtoobesity,bonemineral density,bone turnover markers and vitamin D receptor genotypes in healthy Saudi pre-and postmenopausal women. Osteoporos Int 22(2): 463-475.

67. Alkhenizan A, Mahmoud A, Hussain A, Gabr A, Alsoghayer S, et al.(2017) The relationship between $25(\mathrm{OH}) \mathrm{D}$ levels (Vitamin D) and bone mineral density (BMD) in a Saudi population in a community-based setting. PLoS One 12(1): e0169122. 
68. Al KH, Alissa E(2017) Prevalence of cardiometabolic risk factors among Saudi Women with vitamin D deficiency .Endocrine Abstracts49:292

69. Albar R, Nouran B, Alaa B, Faris A, Abar F, et al.(2017) Prevalence of Vitamin D deficiency in Saudi children and risks of iron deficiency anemia. Current Pediatric Research 21(2): 205-208.

70. Al Daghri NM, Al Attas OS, Alokail MS, Alkharfy KM, Yakout SM, et al.(2014) Lower vitamin D status is more common among Saudi adults with diabetes mellitus type 1 than in non-diabetics. BMC public health 14(1): 153

71. AlOthma A, AlMusharaf S,Soundararajan K, DeqaSY,Khalid MA, etal (2012)Effectofphysicalactivityandsunexposure onvitaminDstatusof Saudi children and adolescents. BMC pediatrics12(1): 92.

72. Elshaf DE,ALKhashan HI, MishrikyAM(2012) Comparison of vitamin D deficiency in Saudimarriedcouple Eur J Clin Nutr66(6):742-745

73. Ullah MI(2010) Does vitamin D deficiency cause hypertension? Current evidence from clinical studies and potential mechanisms. International journal of endocrinology.

74. Kota SK,Jammula S, Meher LK, Panda S, Tripathy PR, et al. (2011) Renin-angiotensin system activity in vitamin D deficient, obese individuals with hypertension: An urban Indian study. Indian J Endocrinol Metab15(Suppl4):S395-S401.

75. Jafari T,Aknahad Z(2014) Vitamin D and hypertension. Zahedan Journal of Research in Medical Sciences16(6): 1-7.

76. Mehta V,Agarwal S (2017) Does vitamin D deficiency lead to hypertension? Cureus, 9(2):e1038.

77. Meyer T, Becker A, Sundermann J, Rothenberger A, Herrmann Lingen C (2017) Attention deficit-hyperactivity disorder is associated with reduced blood pressure and serum vitamin D levels: results from the nationwide German Health Interview and Examination Survey for Children and Adolescents (KiGGS). Eur Child Adolesc Psychiatry 26(2): 165-175.

78. Alfawaz H(2014) Vitamin D status among patients visiting a tertiary care center in Riyadh, Saudi Arabia: a retrospective review of 3475 cases. BMC public health 14(1): 159

79. Al DaghriNM, Alkharfy KM, AlSaleh Y, AlAttas OS, AlokailMS, etal.(2012) Modest reversalofmetabolicsyndromemanifestationswith vitamin D status correction: a 12-month prospective study. Metabolism 61(5): 661666.

80. Kunutsor SK, Apekey TA, Steur M (2013) Vitamin D and risk of future hypertension: meta-analysis of 283,537 participants, Springer. Eur J Epidemiol 28(3):205-221

81. Masala G, Bendinelli B, Occhini D, Bruno RM, Caini S, etal.(2017) Physical activity and blood pressure in 10,000 Mediterranean adults: The EPIC-Florence cohort. NutrMetab Cardiovasc Dis, pp.670-678.

82. Turer CB,Lin H,Flores G (2013) Prevalence of vitamin D deficiency among overweight and obese US children. Pediatrics 131(1): e152-e161.

83. Medina SG, AvelaPérez T, DomínguezGarrido MN, GutiérrezMoreno E, Rovira A,etal. (2015) TheinfluenceofpubertyonvitaminDstatusinobesechildrenand the possible relation between vitamin D deficiency and insulin resistance.J Pediatr Endocrinol Metab28(1-2): 105-110.
84. Kelly A, Brooks LJ, Dougherty S, Carlow DC, ZemelBS (2011) A cross-sectional study of vitamin D and insulin resistance inchildren. Arch Dis Child 96(5): 447-452.

85. Schmitt EB, NahasNeto J, BueloniDias F, Poloni PF, Orsatti CL,et al. (2018) Vitamin D deficiency is associated with metabolic syndrome in postmenopausal women. Maturitas 107: 97-102.

86. Chen S, Sun Y, AgrawalDK(2015) Vitamin D deficiency and essentialhypertension. J Am Soc Hypertens9(11):885-901.

87. Snijder M, Lips P, Seidell JC, Visser M, Deeg DJ, et al.(2007) Vitamin D status and parathyroid hormone levels in relation to blood pressure:apopulation-basedstudyinoldermenandwomen. J Intern Med 261(6):558-565.

88. Hintzpeter B,Mensink GB, Thierfelder W, Müller MJ, ScheidtNave C (2008) Vitamin D status and health correlates among germanadults. Eur I Clin Nutr62(9): 1079-1089

89. Jorde R, Sneve M, Torjesen P, FigenschauY(2010) No improvement in cardiovascular risk factors in overweight and obese subjects after supplementation with vitamin D3 for 1 year. Journal of internal medicine267(5): 462-472.

90. SalehpourA, Farzad S, Farhad H, Mohammadreza V, Maryam R, etal. (2012) VitaminD3andtheriskofCVDinoverweightandobesewomen:a randomised controlled trial. Br J Nutr108(10):1866-1873.

91. AlDaghri NM, AlAttas OS, Johnston HE, Singhania A, Alokail MS, et al.(2014) Whole serum 3D LC-nESI-FTMS quantitative proteomics reveals sexual dimorphism in the milieu interieur of overweight and obese adults.J Proteome Res 13(11):5094-5105.

92. Koundourakis NE,MargiorisAN(2017) Vitamin D and physical activity, ina critical evaluation of vitamin D-basic overview,InTech, pp. 3-44

93. VisserM, Deeg DJ, Puts MT, Seidell JC, Lips P (2006) Low serum concentrations of 25-hydroxyvitamin D in older persons andtheriskofnursinghomeadmission. Am J Clin Nutr84(3):616-622.

94. Al Mheid I, Patel R, Murrow J, Morris A, Rahman A,et al.(2011) Vitamin D status is associated with arterial stiffness and vascular dysfunction in healthy humans. J Am Coll Cardiol58(2):186-192.

95. Acworth I,Nicholass J, Morgan B, Newsholme EA (1986) Effect of sustained exercise on concentrations of plasma aromatic andbranched-chainaminoacidsandbrainamines.BiochemBiophys Res Commun137(1): 149-153.

96. MeeusenR, Watson P, Hasegawa H, Roelands B, Piacentini MF (2006) Central fatigue. Sports Medicine36(10): 881-909.

97. Peters R (2006) Ageing and the brain. Postgrad Med J 82(964): 84-88.

98. Gagnon C, Zhong XL,Dianna JM,David WD,Jonathan ES, et al.(2012)Low serum 25-hydroxyvitamin $\mathrm{D}$ is associated with increased risk of the development of the metabolic syndrome at five years: results from a National, population-based prospective study(TheAustralianDiabetes,ObesityandLifestyleStudy: AusDiab).The Journal of clinical Endocrinology \&Metabolism97(6): 1953-1961.

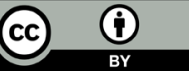

Creative Commons Attribution 4.0 International License

For possible submissions Click Here

\section{Submit Article}

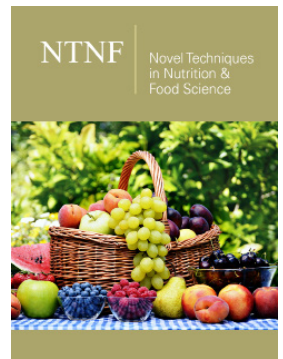

\section{Novel Techniques in Nutrition and Food Science}

\section{Benefits of Publishing with us}

- High-level peer review and editorial services

- Freely accessible online immediately upon publication

- Authors retain the copyright to their work

- Licensing it under a Creative Commons license

- Visibility through different online platforms 